\title{
Comparative study of tribological properties of insulated and conductive polyimide composites
}

\author{
Jingfu SONG ${ }^{1}$, Yuanhao YU' ${ }^{2}$, Gai ZHAO ${ }^{2, *}$, Jinhao QIU ${ }^{2, *}$, Qingjun DING ${ }^{2}$ \\ ${ }^{1}$ College of Material Science and Technology, Nanjing University of Aeronautics and Astronautics, Nanjing 210016, China \\ ${ }^{2}$ State Key Laboratory of Mechanics and Control of Mechanical Structures, Nanjing University of Aeronautics and Astronautics, Nanjing \\ 210016, China
}

Received: 12 October 2018 / Revised: 15 December 2018 / Accepted: 28 December 2018

(C) The author(s) 2019.

\begin{abstract}
Insulated polyimide (PI) composites filled with short glass fibers (SGF), polytetrafluoroethylene (PTFE), $\mathrm{SiO}_{2}$, and polyphenylene (PPL) are specially designed, prepared, and the tribological properties are systematically investigated with references to the special requirements for frictional materials used in ultrasonic motors. The hardness and thermal decomposition temperature of the insulated PI composites are comparable to that of conductive PI composites. However, these insulated materials present excellent friction and wear performance, especially under high loads and speeds. Scanning electron microscopy (SEM) analysis of the worn surface indicates that adhesive and fatigue wear dominate the wear mechanisms.
\end{abstract}

Keywords: polyimide composites; insulation; friction; wear

\section{Introduction}

Ultrasonic motors (USMs) driven by the friction force between stator and rotor are becoming increasingly popular for use in medical applications, precision positioning, and aerospace engineering owing to their desirable properties, such as fast response, high torque at low speed, self-locking without requiring power, and flexible structure [1]. With the increasing popularity of USMs, tribo-materials are expected to have several desirable properties, such as high temperature resistance, exceptionally long service life, high strength, and radiation resistance. Frictional materials are core components of USMs, and can directly determine their mechanical output characteristics and service life. They also affect the stability and reliability of the entire driving system indirectly. Thus, frictional materials are one of the key factors that limit the development of USMs.

In the past decades, majority of the researchers devoted their efforts to the development of new frictional materials or modification of tribo-interfaces [2-5]. Traditionally, certain polymer composites were employed as friction materials in traveling wave USMs in order to prolong their service life. Common methods for improving the wear resistance of such polymers included filling using fibers, solid lubricants, and nanoparticles. In composites, the fibers carry the applied load, while the solid lubricants improve the wear resistance of the polymer. In the early stage of USM development, Rehhein and Wallaschek [6] studied the friction and wear behavior of polyimide (PI) composites as frictional materials and found that filling carbon fibers could improve the wear resistance of PI sliding against steel. Concurrently, Ishii et al. [7] presented a method to predict the service life of USMs that use carbon fiber reinforced polymer as frictional materials, which was verified by the experiment. Subsequently, Lv et al. [8-14] researched a series of polymer-based frictional materials, such as polytetrafluoroethylene (PTFE), phenolic resin, and Ekonol composites, and compared their tribological properties

* Corresponding authors: Gai ZHAO, E-mail: zhaogai@nuaa.edu.cn; Jinhao QIU, E-mail: qiu@nuaa.edu.cn 
under different conditions to provide guidance for selecting frictional materials according to the operating condition. Wang et al. [15, 16] systematically studied the effect of fillers, topography, temperature, and vacuum on the wear behavior of PTFE composites and found that filling some functional additives could improve the wear resistance of the PTFE matrix. High temperature and pressure strongly affect the wear mechanisms of PTFE-based frictional materials. In our previous studies [17-19], we designed some PI-based frictional materials with different tribological properties. However, it was difficult for these traditional frictional materials to meet the insulation requirements of the satellite system if it was modified using conductive fillers. Because the frictional materials in the USM stator that slides with the metal (a conductive material as a ground electrode) is running under a strong electric field, the current passing through frictional materials will affect the entire satellite system in the absence of suitable insulation. So, design of insulated frictional materials has an important role in the insulation of ultrasonic motors.

In the case of frictional materials, there are a few reports about polymer-based frictional materials. Until now, Fan et al. [20] prepared polyvinylidene fluoride (PVDF) and PTW/PTFE composites, which could improve the anti-wear ability of USM. Lin prepared PBT hybrid composites without filling solid lubricants, and compared their friction and wear behavior. They found that PBT-based tribo-compounds filled with short carbon fibers (SCF) and rigid particles without graphite still had excellent wear resistance. However, no literature reported insulated polyimide hybrid material. In our current work, we chose the PI matrix due to its excellent mechanical strength, thermal stability, high wear resistance, etc. Subsequently, insulated PI tribo-materials without the SCF and graphite filling were specially designed and their mechanical, thermal, and tribological properties were comprehensively compared with the corresponding conductive materials. The main aim of this study is to reveal the wear mechanisms to understand how isolated fillers produce the same lubrication effect, which can provide guidance for the design of high performance insulated frictional materials specially for USM applications.

\section{Experimental}

\subsection{Materials}

In this study, PI composites were prepared for use in USMs. PI YS-20 grade powder having average particle size $<75 \mu \mathrm{m}$ was supplied by Shanghai Synthetic Resin Institute (China). The chemical structure and properties of PI is shown in our previous study [17]. SCF were obtained from Nantong Senyou Carbon Fiber Co., Ltd. (China). The length of the fibers ranged from $20 \mu \mathrm{m}$ to $50 \mu \mathrm{m}$ and the diameter was approximately $7 \mu \mathrm{m}$. SGF were supplied by Nanjing Institute of Glass Fiber Research and Design (China). The diameter of the fiber was $10 \mu \mathrm{m}$ and the aspect ratio was 10:1. Flaky graphite powders $(<1.5 \mu \mathrm{m})$ was provided by Shanghai Colloid Chemical Plant (China). The PTFE powders (M18F, average diameter of $75 \mu \mathrm{m}$ ) were obtained from Daikin Fluorochemicals Co., Ltd. (China). $\mathrm{SiO}_{2}$ powders $(500 \mathrm{~nm}$ ) were purchased from Sigma-Aldrich. Polyphenylene (PPL) powders $(<75 \mu \mathrm{m})$ were purchased from Jiangsu Guorong Fluorine Plastic Products Co., Ltd. (China). Figure 1 shows the scanning electron microscope (SEM) morphologies of CF, GF, and $\mathrm{SiO}_{2}$. The volume and function of the individual components are listed in Table 1. The conductive PI composite was named as PI-1, and the insulated PI composite was designated as PI-2. Some key parameters of the two types of polyimide composites are listed in Table 2.

The PI composites were fabricated using the conventional hot press sintering technique. Firstly, the PI powders and all fillers were dispersed in ethanol by mechanical stirring followed by placing in an ultrasonic bath for $2 \mathrm{~h}$, and dried in a vacuum oven for use. Then, the mixtures were compressed in a mold and heated up to $375^{\circ} \mathrm{C}$ with intermittent deflation. The pressure was held at $20 \mathrm{MPa}$ for $60 \mathrm{~min}$ to allow completely compressed sintering. Finally, the specimens were cut into different sizes for experiments after natural cooling. As can be seen from the fracture surface in Fig. 2, the PI composites were successfully prepared. Some fibers can be clearly seen on the fracture surface of the polymer composites. The other fillers without obvious morphologies may be coated by the polymer matrix. Generally, there was no cavitation or agglomeration on the surface, which indicated the even 

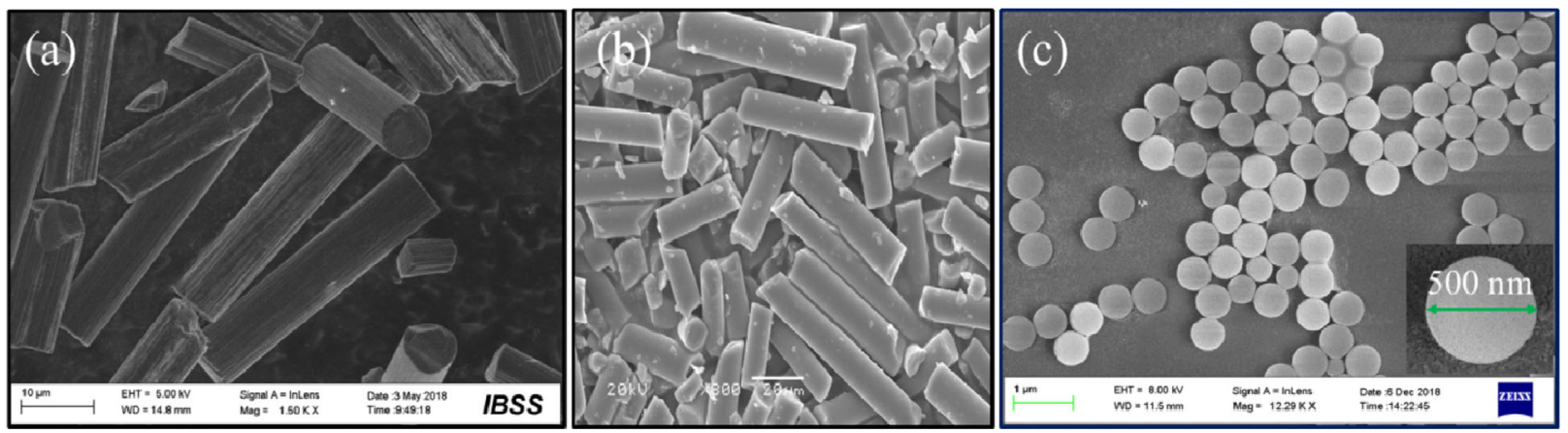

Fig. 1 SEM morphologies of (a) CF, (b) GF, and (c) $\mathrm{SiO}_{2}$.

Table 1 Compositions of the tribo-materials.

$(\mathrm{vol} \%)$

\begin{tabular}{cccccccc}
\hline Sample & PI & SCF & SGF & Graphite & PTFE & $\mathrm{SiO}_{2}$ & PPL \\
\hline PI-1 & 69 & 15 & - & 10 & - & 1 & 5 \\
PI-2 & 69 & - & 15 & - & 10 & 1 & 5
\end{tabular}

Function Matrix Reinforce Reinforce Lubricants Lubricants + low surface energy Fortifier $\quad$ Thermal stability

Table 2 Some main parameters of PI composites.

\begin{tabular}{ccccc}
\hline Sample & Tensile strength (MPa) & Elongation percentage (\%) & Elastic modulus (GPa) & Electrical resistance \\
\hline PI-1 & 273.4 & 5.3 & 13.47 & $300 \Omega-400 \Omega$ \\
PI-2 & 225.2 & 6.2 & 9.23 & $\propto$ \\
\hline
\end{tabular}
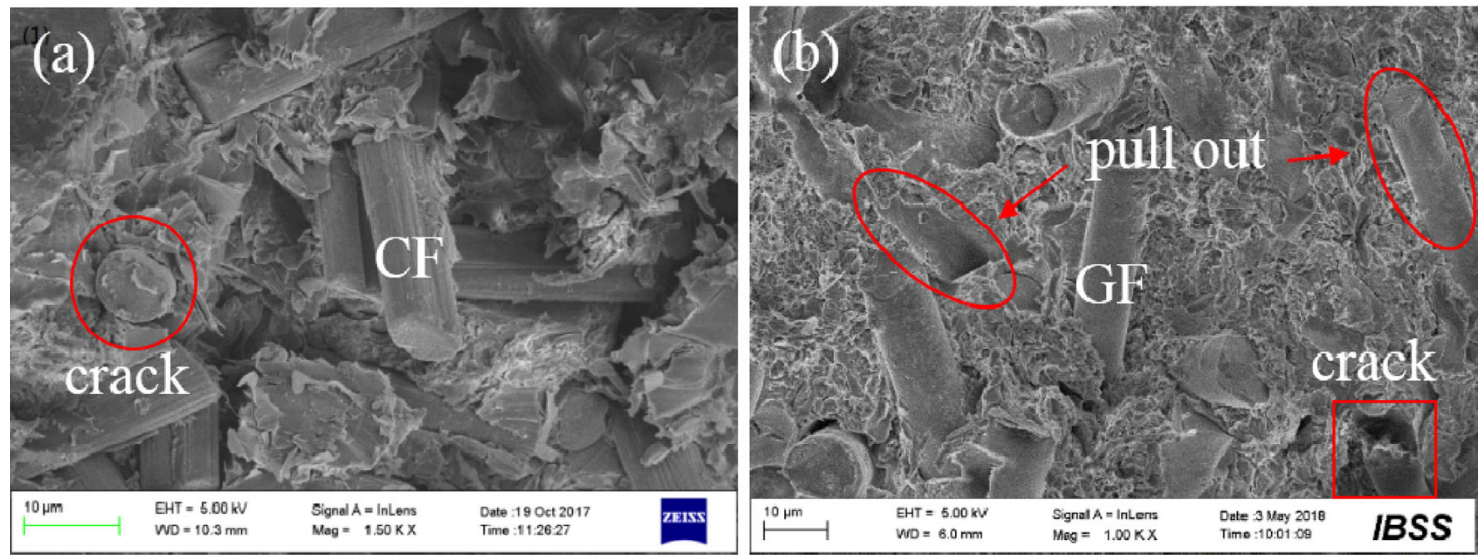

Fig. 2 Fracture morphologies of the polyimide composites: (a) PI-1 and (b) PI-2.

distribution of fillers into the PI matrix. Before tribotests, the PI composites were polished by metallographic sandpaper to a roughness below $0.1 \mu \mathrm{m}$.

\subsection{Friction and wear tests}

The friction and wear tests involving sliding against a $\mathrm{Si}_{3} \mathrm{~N}_{4}$ ball were evaluated on a ball-on-disk tribometer (HSR-2M, China) referred to the ASTM G99-04 Pin-on-Disk pattern at room temperature. The schematic diagram of the friction couple is shown in Fig. 3. The

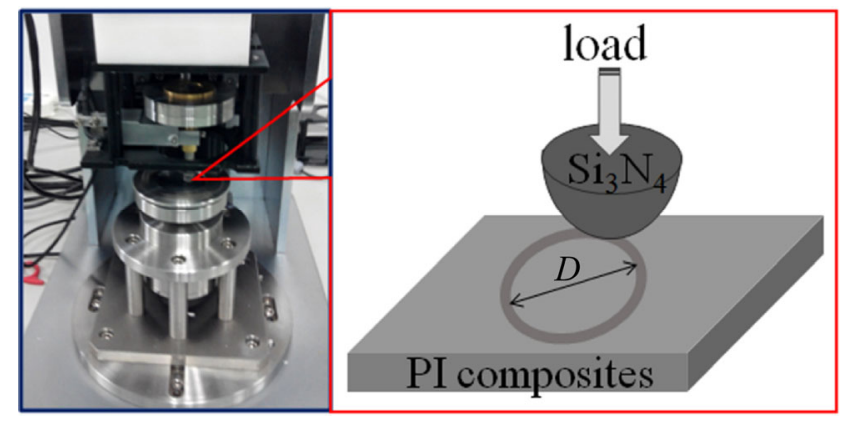

Fig. 3 Photograph of the tribo-meter and schematic of wear test. 
$\mathrm{Si}_{3} \mathrm{~N}_{4}$ ball is $4 \mathrm{~mm}$ in diameter. Before each test, the $\mathrm{Si}_{3} \mathrm{~N}_{4}$ ball and the block samples were cleaned with cotton dipped in acetone. The wear volume was computed from the cross-sectional worn area multiplied by the circumference of the wear track and calculated using Eq. (1). The specific wear rate $\mathrm{K}\left(\mathrm{mm}^{3} / \mathrm{N} \cdot \mathrm{m}\right)$ was calculated from the volume loss using Eq. (2).

$$
\begin{gathered}
\Delta V=\left[\frac{\pi(R / 2)^{2}}{180} \arcsin \frac{b}{R}-\frac{b \sqrt{(R / 2)^{2}-(b / 2)^{2}}}{2}\right] \pi D \\
K=\frac{\Delta V}{P L}
\end{gathered}
$$

where $\Delta V$ is the wear volume loss $\left(\mathrm{mm}^{3}\right), R$ is the diameter of the ball $(4 \mathrm{~mm}), b$ is the width of the wear track $(\mathrm{mm}), D$ is the diameter of the disk $(6 \mathrm{~mm}) . P$ is the load $(\mathrm{N})$, and $L$ is the total sliding distance $(\mathrm{m})$. The coefficient of friction, which taken on the average value in the steady stage, was continuously recorded by an on-line data acquisition system attached to the tester.

\subsection{Characterization}

The hardness was measured using Shore D (SD) tester. Each sample was tested ten times and the average value was used. The tensile strength of the samples were measured using a universal tensile testing machine (SANS-CMT5, Shenzhen Sans Testing Machine Co., Ltd., China), according to Fiber-reinforced plastics composites-Determination of tensile properties (GB/T 14472005) and repeated at least three times. The average value was used for subsequent computations. The electrical resistance was measured by a multimeter at different points of the PI composite specimens. Thermo gravimetric analysis (TGA) and differential scanning calorimetry tests were carried out under a $\mathrm{N}_{2}$ atmosphere with a Netzsch TG 209 on 19 TASC 41441 analyzer (Germany) from $40{ }^{\circ} \mathrm{C}$ to $800{ }^{\circ} \mathrm{C}$ with a heating rate of $10{ }^{\circ} \mathrm{C} / \mathrm{min}$. The width of the worn track was measured under an optical microscope (VHX-1000 3D ultra-depth of field microscope, Japan) to calculate the wear rate. The worn surface morphologies of the samples were observed using a Zeiss-sigma (Germany) SEM. In order to increase the resolution of SEM observation, the surfaces were plated with a gold coating to render them electrically conductive.

\section{Results and discussion}

\subsection{Hardness}

Figure 4 shows the hardness (SD) of polyimide composites. Compared with PI-1, the hardness of PI-2 decreased slightly due to the addition of PTFE as it has a relatively lower modulus and hardness than PI [21]. That will affect the thermal and tribological properties of the composites. The detailed experimental results are presented in the section.

\subsection{Thermo gravimetric analysis}

In order to analyze the thermal stability of the PI composites, Fig. 5 shows the similarity of the thermo gravimetric analysis curves of two kinds of materials from $40{ }^{\circ} \mathrm{C}$ to $800{ }^{\circ} \mathrm{C}$. The decomposition temperature of the composites mainly depends on the polyimide matrix $\left(564{ }^{\circ} \mathrm{C}\right)$ [19]. The incorporation of other fillers will affect the actual decomposition temperature and residual mass. For PI-1, the rate of decomposition reached the peak value when the temperature rose to $548.6{ }^{\circ} \mathrm{C}$ and the residual mass was $74.35 \%$ after $800{ }^{\circ} \mathrm{C}$.

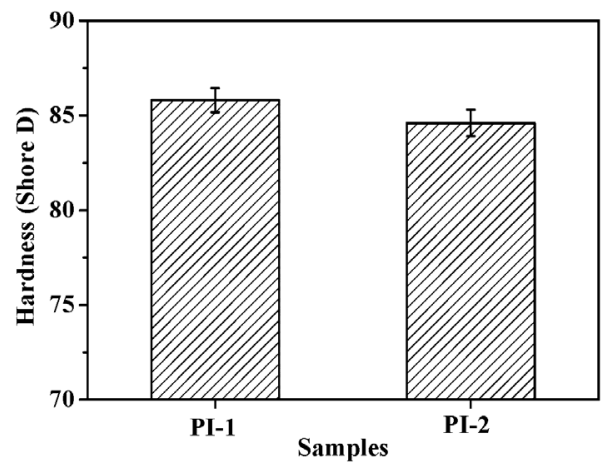

Fig. 4 Hardness of PI composites.

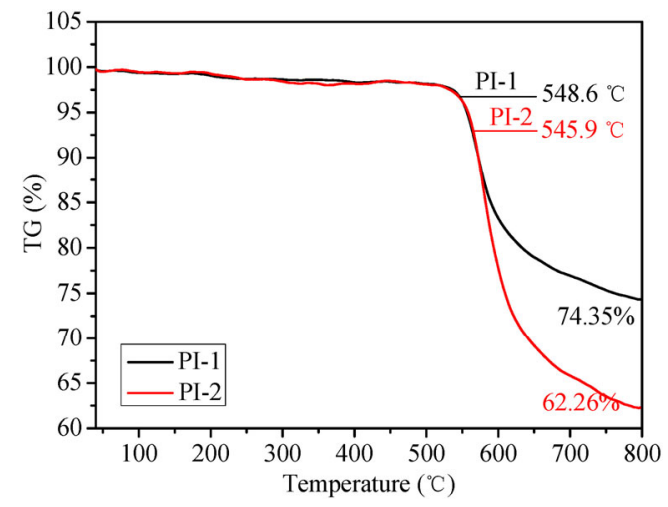

Fig. 5 TGA curves of the polyimide composites. 
But PI-2 had the maximum rate of decomposition at $545.9^{\circ} \mathrm{C}$ and $62.26 \%$ residual mass. The main difference between PI-1 and PI-2 was the difference in the composition of the fibers and solid lubricants. As far as fibers in the composite are concerned, both glass fibers and carbon fibers have excellent thermal resistance. So, the dominant reason for the variation can be identified as the addition of PTFE that had a relatively low decomposition temperature of approximately $460{ }^{\circ} \mathrm{C}$ according to Sun et al. [22]. So, introducing PTFE into the polyimide composite will reduce the decomposition temperature slightly and the residual mass by approximately $12.09 \%$.

\subsection{Friction and wear behavior}

The tribological properties of the two composites were systematically compared to evaluate the wear resistance under different operating conditions. Firstly, the friction and wear tests were performed at the speed of $0.063 \mathrm{~m} / \mathrm{s}$ and the load of $3 \mathrm{~N}$ under rotating wear. The total test duration is taken as $6 \mathrm{~h}$ to acquire the reliable data in the stable stage with the rotating radius of $3 \mathrm{~mm}$. Figure 6 shows the variation of the coefficient of friction with time. It can be clearly seen that PI-2 has a smaller friction coefficient than PI-1. This can be ascribed to the excellent lubrication effect of PTFE. Judging from the variation of the friction coefficient of PI composites, PI-1 shows more stable friction behavior than PI-2, because the added graphite in the PI composites was easily transferred onto the surface of the counterpart. So, PI-1 will become stable in short running time. However, the friction coefficient of PI-2 filled with PTFE continuously increased with

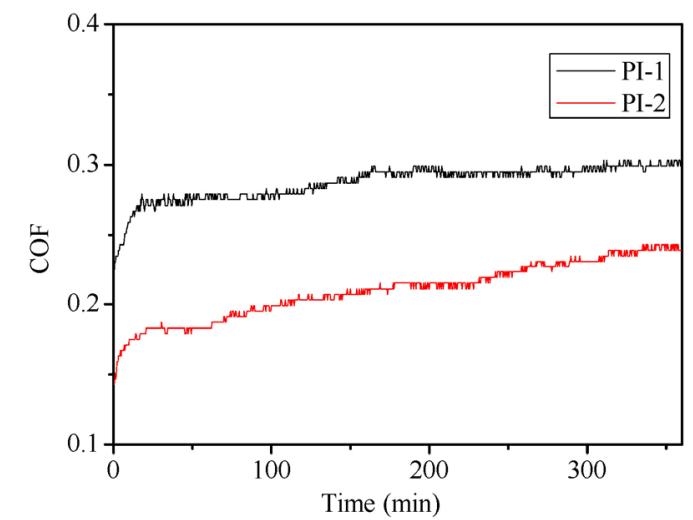

Fig. 6 Friction coefficient of PI composites under $3 \mathrm{~N}$ and $0.063 \mathrm{~m} / \mathrm{s}$. time, and required longer time to attain stability. The fundamental reason can be ascribed to the difference in the materials. For polymer composites reinforced with fibers, some fibers will be exposed on the surface of the polymer after the superficial polymer matrix wears off. Then, the shear stress concentrates on the fibers that carry most of the applied load, while shielding the polymer. PI-2, which is reinforced with glass fibers, had a higher surface hardness and better wear resistance than PI-1. It indicates that PI-2 needs a longer time to reach the same wear volume under the same wear testing time than PI-1 [23]. The area of contact between the $\mathrm{Si}_{3} \mathrm{~N}_{4}$ ball and PI-2 will enlarge with time. It has been reported that increase in the area of contact can lead to the increase in material transfer and increment in the friction coefficient [11]. So, the friction coefficient of PI-2 increases with time.

The same phenomenon can be observed from Fig. 7 under high loads and speeds. The PI-2 showed a smaller friction coefficient than PI-1 under the same conditions. In addition, high load and speed contributed to the reduction of friction for both composites. The effect of speed and load on the friction of the PI composites was also tested and compared.

As seen from Fig. 8, the friction coefficient of the PI composites decreased with an increase of speed from $0.063 \mathrm{~m} / \mathrm{s}$ to $0.157 \mathrm{~m} / \mathrm{s}$ under the load of $3 \mathrm{~N}$ with a duration of $6 \mathrm{~h}$. It is obvious that an increase of speed will result in the rise of temperature on the surface of the PI composites. The higher the testing speed, the faster the accumulation of frictional heat at the friction surface. Rising temperature leads to the softening of some polymer molecular chains, which can result in

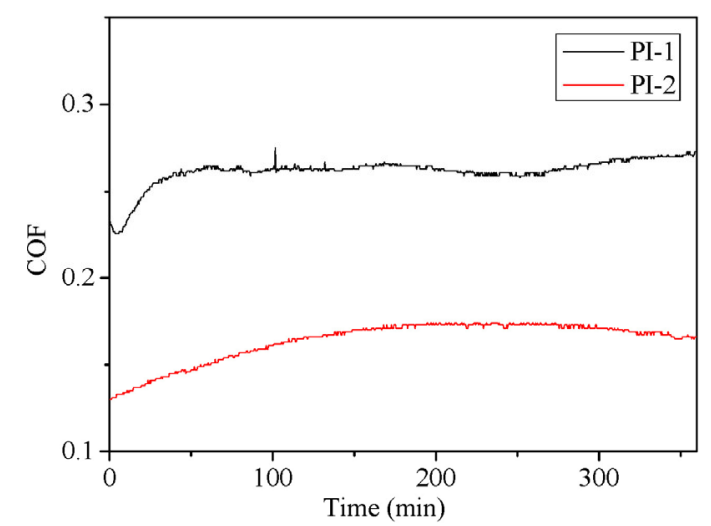

Fig. 7 Friction coefficient of PI composites under $9 \mathrm{~N}$ and $0.157 \mathrm{~m} / \mathrm{s}$. 


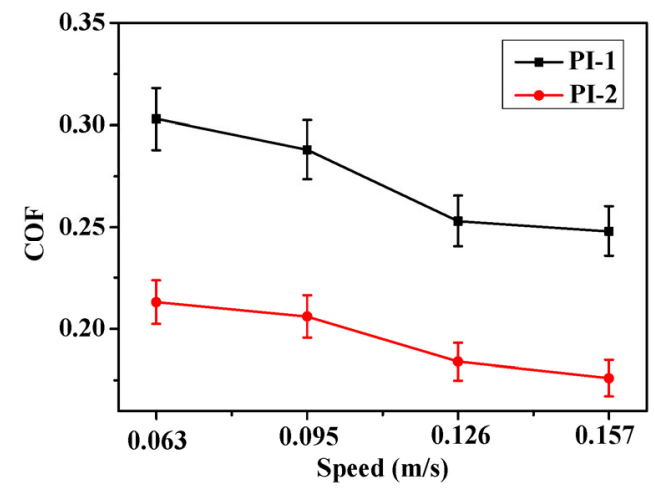

Fig. 8 Average friction coefficient of PI composites under different speeds.

a reduction of the friction coefficient [24, 25]. Besides, it can be clearly seen that PI-2 had a lower friction coefficient than PI-1 under the same testing conditions, which was determined by their essential properties. The fundamental reason can be attributed to the addition of glass fibers and PTFE into PI composites.

Except for the speed of rotation, the applied load was one of the most important factors affecting the tribological properties of polymer composites. In this study, the friction coefficient of PI composites decreased sharply when the applied load increased from $3 \mathrm{~N}$ to $5 \mathrm{~N}$ at a constant speed of $0.063 \mathrm{~m} / \mathrm{s}$ with a duration of $6 \mathrm{~h}$ as shown in Fig. 9. Then, they had relatively small variations from $5 \mathrm{~N}$ to $9 \mathrm{~N}$. Firstly, the high applied load will contribute to the increase of the actual area of contact between the $\mathrm{Si}_{3} \mathrm{~N}_{4}$ ball and polymer composite because of elastic and plastic deformation. Reduction of the frictional force was detrimental for the tribopairs. However, the increasing amplitude of frictional force was generally smaller than the applied load. So, the friction coefficient of system will decrease with an

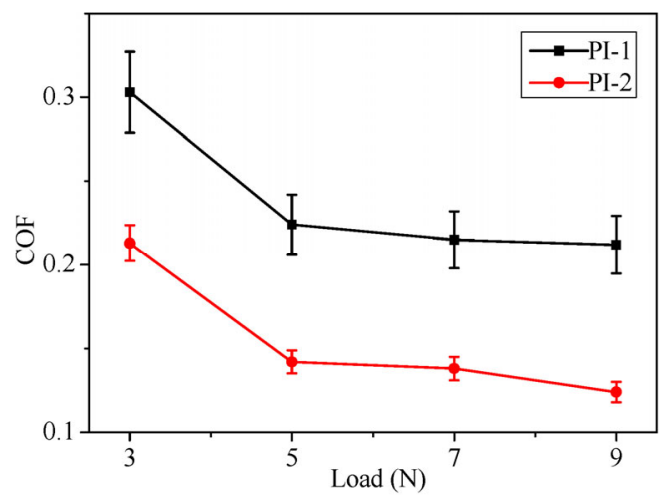

Fig. 9 Average friction coefficient of PI composites under different loads. increase in the load. Besides, the frictional heat cannot be ignored, especially under high load as the high flash temperature on the tips of the rough surface of the polyimide composites was enough to make partial polyimide molecular chain soft, or even molten under the combined effect of speed and ambient temperature. Soft polymer chains will reduce the shear stress and improve the lubrication of the tribo-system. So, increasing the load will reduce the friction coefficient of the polyimide composite for both insulating and conductive tribo-materials.

Except for the friction that will vary with the speed of rotation and load, the wear behavior should be sensitive to the operating conditions. In this study, the specific wear rate was calculated along the wear track and compared by selecting typical low $(3 \mathrm{~N}$, $0.063 \mathrm{~m} / \mathrm{s})$ and high $(9 \mathrm{~N}, 0.157 \mathrm{~m} / \mathrm{s})$ load and speed values. The aim is to obtain the wear resistance of two types of PI composites under the same conditions. Firstly, the wear width was measured using optical microscopy as shown in Fig. 10. Then, the wear volume loss was calculated using Eq. (1). Finally, the average specific wear rate with the standard error can be obtained from Eq. (2) under a certain load and sliding distance. As seen from Fig. 11, the PI-1 had a high wear rate $\left(3.84 \times 10^{-6} \mathrm{~mm}^{3} / \mathrm{N} \cdot \mathrm{m}\right)$ under $0.063 \mathrm{~m} / \mathrm{s}$ and $3 \mathrm{~N}$. By contrast, the insulated PI-2 had a low wear rate of approximately $2.03 \times 10^{-6} \mathrm{~mm}^{3} / \mathrm{N} \cdot \mathrm{m}$, decreased by $47.14 \%$. It indicated that substituting the $\mathrm{CF}$ and graphite with GF and PTFE could improve the wear resistance of PI composites under the synergistic effect of $\mathrm{SiO}_{2}$ and PPL. Comparable results can be obtained under $9 \mathrm{~N}$ and $0.157 \mathrm{~m} / \mathrm{s}$. The specific wear rate of PI-2 decreased from $1.92 \times 10^{-6} \mathrm{~mm}^{3} / \mathrm{N} \cdot \mathrm{m}$ to $0.81 \times 10^{-6} \mathrm{~mm}^{3} / \mathrm{N} \cdot \mathrm{m}$. This

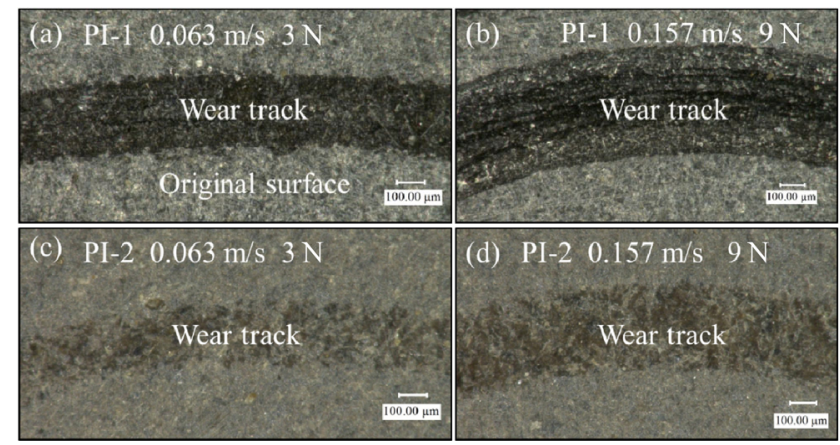

Fig. 10 Optical microscopies of wear track of PI composites. (a) PI-1 and (c) PI-2 under $0.063 \mathrm{~m} / \mathrm{s}$ and $3 \mathrm{~N}$, (b) PI-1 and (d) PI-2 under $0.157 \mathrm{~m} / \mathrm{s}$ and $9 \mathrm{~N}$. 


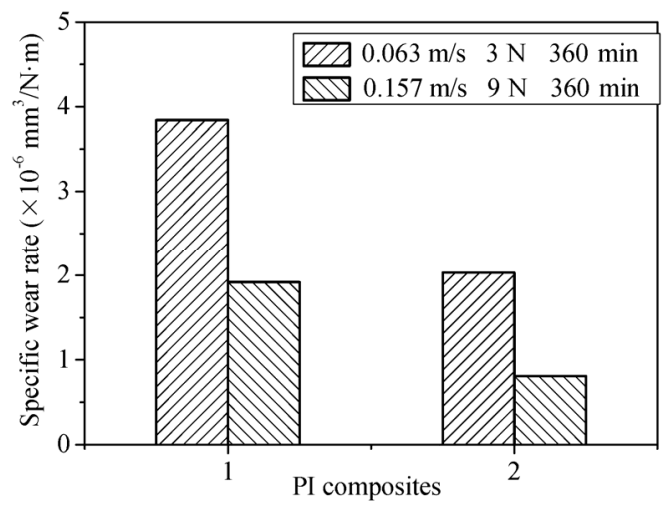

Fig. 11 Specific wear rate of PI composites under different conditions.

can be ascribed to the excellent self-lubrication effect of PTFE and good compatibility with the PI matrix. In summary, this insulation design for a PI composite has the potential to reduce the friction and improve the wear resistance, as evidenced by the above discussion about friction coefficient and change in wear rate.

To discover wear mechanisms, the worn morphologies of PI composites under different conditions were observed by SEM as shown in Fig. 12. It can be clearly seen that the worn surfaces of the PI composites are completely different from the original surface. For PI-1, the worn surface morphologies shown in Figs. 12(b) and 12(c) seem more smooth and homogenous after $6 \mathrm{~h}$ of rotating wear compared with the original surface (Fig. 12(a)). Under the load of $3 \mathrm{~N}$ and $0.063 \mathrm{~m} / \mathrm{s}$, the worn surface was comparatively smooth because the asperities on the original rough surface were worn off. During this process, adhesive wear was dominant in the beginning, after which a steady state was attained when the tribo-films were formulated between the PI samples and counterpart. However, under the high load $(9 \mathrm{~N})$ and speed $(0.157 \mathrm{~m} / \mathrm{s})$, some cracks were formed on the worn surface (Fig. 12(c)) due to fatigue wear. This explains the higher wear rate shown by PI-1 with respect to PI-2. For PI-2, the surface structure was different from PI-1 because of the addition of different fillers, especially the incorporation of glass fibers and PTFE. There were plenty of wrinkles on the worn surface as can be seen from Figs. 12(e) and 12(f). This phenomenon suggested that plastic deformation happened on the worn surface under the repeated shear stress, which is related to their mechanical and thermal properties. As discussed in Sections 3.1 and 3.2, PI-2 had lower hardness and decomposition temperature than PI-1. Compared with the worn surface under the relatively low load $(3 \mathrm{~N})$ and speed $(0.063 \mathrm{~m} / \mathrm{s})$, more severe cracks were found on the worn surface under the high load $(9 \mathrm{~N})$ and speed $(0.157 \mathrm{~m} / \mathrm{s})$. For the PTFE filled PI composite, adhesive and fatigue wear together dominated the wear process. However, according to Eqs. (1) and (2), the specific wear rate did not increase exponentially with the load and speed. Hence, the specific wear rate will decrease under a high load and speed. This is consistent with the results of wear rate shown in Fig. 11.
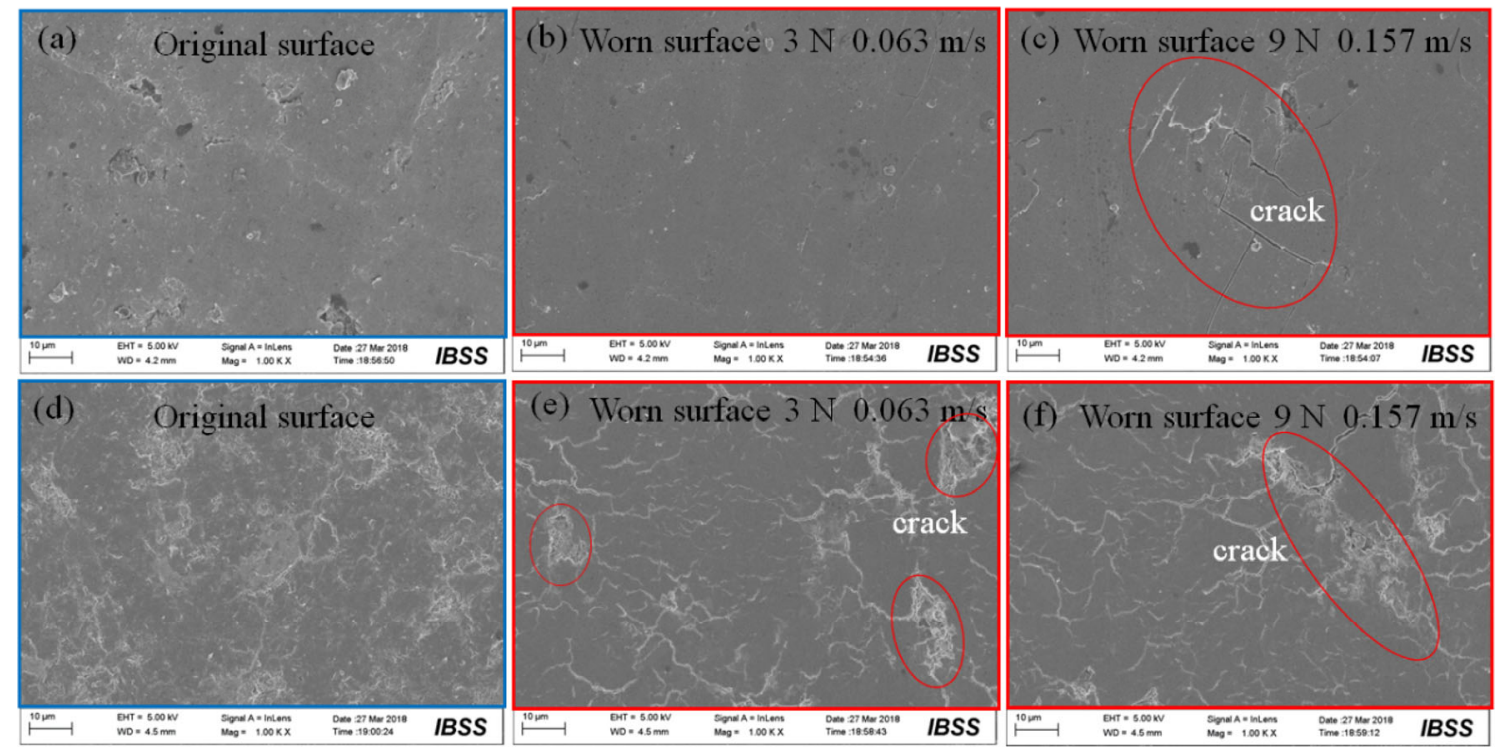

Fig. 12 Original surface (a) PI-1 and (d) PI-2, and worn surface morphologies of the polyimide composites (b, c) PI-1 and (e, f) PI-2. 


\section{Conclusions}

The mechanical, thermal, and tribological properties of insulated and conductive PI composites were systematically compared and discussed. Although the conductive polyimide composites can be used as tribo-materials for USMs under normal conditions, the new polyimide composites after insulation design can also satisfy the requirements of low friction and wear rate. The substitution of carbon fibers and graphite with glass fibers and PTFE did not greatly affect the hardness and thermal decomposition temperature for this PI composite, which, contrarily, reduce the friction and wear rate analyzed from tribo-tests and worn surface characterization. Different wear mechanisms dominated the wear process of these two PI composites. The synergistic effect of glass fibers, PTFE, $\mathrm{SiO}_{2}$ and PPL will contribute to the excellent tribological performance of the PI matrix, which can provide significant guidance for designing other types of insulated polymer composites.

\section{Acknowledgements}

This work is supported by the Fundamental Research Funds for the Central Universities (NS2018010), the Major State Basic Research Development Program of China (973 Program, Grant No. 2015CB057501), and a project funded by the Priority Academic Program Development of Jiangsu Higher Education Institutions.

Open Access This article is licensed under a Creative Commons Attribution 4.0 International License, which permits use, sharing, adaptation, distribution and reproduction in any medium or format, as long as you give appropriate credit to the original author(s) and the source, provide a link to the Creative Commons licence, and indicate if changes were made.

The images or other third party material in this article are included in the article's Creative Commons licence, unless indicated otherwise in a credit line to the material. If material is not included in the article's Creative Commons licence and your intended use is not permitted by statutory regulation or exceeds the permitted use, you will need to obtain permission directly from the copyright holder.
To view a copy of this licence, visit http://creativecommons.org/licenses/by/4.0/.

\section{References}

[1] Zhao C S. Ultrasonic Motors: Technologies and Applications. Berlin Heidelberg (Germany): Speinger-Verlag, 2011.

[2] Wu J, Mizuno Y, Tabaru M, Nakamura K. Traveling wave ultrasonic motor using polymer-based vibrator. Jpn J Appl Phys 55(1): 018001 (2016)

[3] Wu J, Mizuno Y, Tabaru M, Nakamura K. Ultrasonic motors with polymer-based vibrators. IEEE Trans Ultrason Ferroelectr Freq Control 62(12): 2169-2178 (2015)

[4] Qiu W, Mizuno Y, Nakamura K. Tribological performance of ceramics in lubricated ultrasonic motors. Wear 352-353: 188-195 (2016)

[5] Li J B, Zhou N N, Yu A B, Cui Y G. Tribological behavior of CF/PTFE composite and anodized Al-rotor in traveling wave ultrasonic motors. Tribol Lett 65(1): 4 (2017)

[6] Rehbein P, Wallaschek J. Friction and wear behaviour of polymer/steel and alumina/alumina under high-frequency fretting conditions. Wear 216(2): 97-105 (1998)

[7] Ishii T, Takahashi H, Nakamura K, Ueha S, Ohnishi K. Wear prediction method of the friction materials used for the ultrasonic motors. J Jpn Soc Tribol 45(1): 62-71 (2000)

[8] Lv M, Han F, Wang Q H, Wang T M, Liang Y M. The structure properties and tribological behavior of the ionic liquid-polyimide composite films under high-vacuum environment. High Perform Polym 29(2): 170-177 (2017)

[9] Qu J J, Zhang Y H, Tian X, Li J B. Wear behavior of filled polymers for ultrasonic motor in vacuum environments. Wear 322-323: 108-116 (2015)

[10] Mohan R, Das B N, Sundaresan R. Effect of hardness and surface roughness on slip resistance of rubber. J Test Eval 43(6): 1574-1586 (2015)

[11] Rahaman M L, Zhang L C, Liu M, Liu W D. Surface roughness effect on the friction and wear of bulk metallic glasses. Wear 332-333: 1231-1237 (2015)

[12] Qu Y Y, Zhang Y H, Qu J J. Micro-driving behavior of carbon-fiber-reinforced epoxy resin for standing-wave ultrasonic motor. Polym Compos 37(7): 2152-2159 (2016)

[13] Li J B, Qu J J, Zhang Y H, Wang J X. Mechanical and electrical characteristics of traveling wave ultrasonic motors during the whole life of friction material. Proc Inst Mech Eng Part J J Eng Tribol 230(8): 907-918 (2016)

[14] Li J B, Qu J J, Zhang Y H. Wear properties of brass and PTFE-matrix composite in traveling wave ultrasonic motors. Wear 338-339: 385-393 (2015) 
[15] Wang Q H, Song F Z, Zhang X R, Zhao G, Wang T M. Impact of fillers and counterface topography on wear behavior of PTFE polymers for ultrasonic motor. J Appl Polym Sci 134(19): 44835 (2017)

[16] Song F Z, Yang Z H, Zhao G, Wang Q H, Zhang X R, Wang T M. Tribological performance of filled PTFE-based friction material for ultrasonic motor under different temperature and vacuum degrees. J Appl Polym Sci 134(39): 45358 (2017)

[17] Zhao G, Ding Q J, Wang Q H. Comparative study on the tribological properties of the polyimide composites reinforced with different fibers. Polym Compos 37(8): 2541-2548 (2016)

[18] Zhao G, Hussainova I, Antonov M, Wang Q H, Wang T M. Friction and wear of fiber reinforced polyimide composites. Wear 301(1-2): 122-129 (2013)

[19] Zhao G, Hussainova I, Antonov M, Wang Q H, Wang T M, Yung D L. Effect of temperature on sliding and erosive wear of fiber reinforced polyimide hybrids. Tribol Int 82(B): 525-533 (2015)

[20] Fan Y, Ding Q J, Yao Z Y. Properties of potassium titanate whisker reinforced polytetrafluoroethylene-based friction

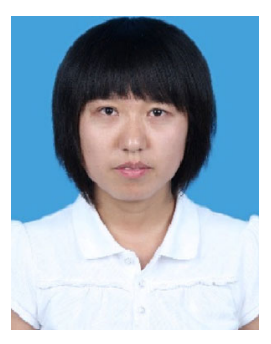

Jingfu SONG. She received her master degree in physical chemistry from Lanzhou Institute of Chemical Physics, Chinese Academy of Science, China, in 2011. Since 2016, she

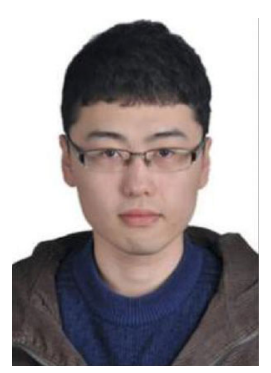

Yuanhao YU. He received his bachelor degree in aeronautics Engineering in 2016 from North University of China, Taiyuan, Shanxi province, China. Then he joined the State Key Laboratory of Mechanics materials of ultrasonic motors. J Appl Polym Sci 125(5): 3313-3317 (2012)

[21] Zhao G, Wu C H, Zhang L C, Song J F, Ding Q J. Friction and wear behavior of PI and PTFE composites for ultrasonic motors. Polym Adv Technol 29(5): 1487-1496 (2018)

[22] Sun L L, Zhang Z G, Zhong W H. Fluorination deposition on carbon nanofibers by PTFE decomposition as a facile method to enhance dispersion and interaction in PVDF composites. J Mater Chem 21(4): 944-950 (2011)

[23] Song F Z, Wang Q H, Wang T M. Effects of glass fiber and molybdenum disulfide on tribological behaviors and PV limit of chopped carbon fiber reinforced Polytetrafluoroethylene composites. Tribol Int 104: 392-401 (2016)

[24] Zhao G, Wang T M, Wang Q H. Surface modification of carbon fiber and its effects on the mechanical and tribological properties of the polyurethane composites. Polym Compos 32(11): 1726-1733 (2011)

[25] Li D X, Deng X, Wang J, Yang J, Li X X. Mechanical and tribological properties of polyamide 6-polyurethane block copolymer reinforced with short glass fibers. Wear 269(3-4): 262-268 (2010)

pursued her Ph.D at Nanjing University of Aeronautics and Astronautics majored in materials science and engineering, China. Her research interests include tribology of polymer composites and molecular dynamics (MD) simulations.

and Control of Mechanical Structures, at Nanjing University of Aeronautics and Astronautics for his master degree. His research interest includes tribology of polymer nanocomposites. 


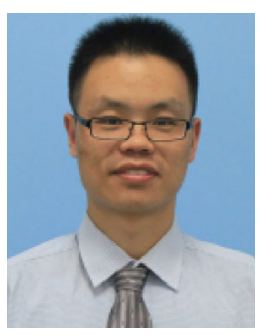

Gai ZHAO. He received his Ph.D degree in physical chemistry from Lanzhou Institute of Chemical Physics, Chinese Academy of Science, China, in 2013. He joined the State Key Laboratory of Mechanics and Control

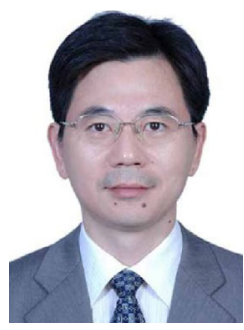

Jinhao QIU. He received his bachelor and master degrees in mechanical engineering from Nanjing University of Aeronautics and Astronautics, China, in 1983 and 1986 respectively, and the Ph.D degree in mechanical engineering from Tohoku University, Japan, in 1996. He was a research associate from 1986 to 1989 and a lecturer (1990 to 1991) at Department of Mechanical Engineering, Nanjing University of Aeronautics and Astronautics. He was a faculty member at the Institute of Fluid Science, Tohoku University from 1992 to 2006, where he was a research

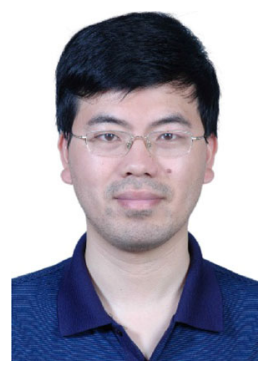

Qingjun DING. He received his Ph.D degree in chemistry from Nanjing University, China, in 2005. He joined Nanjing University of of Mechanical Structures at Nanjing University of Aeronautics and Astronautics from 2013. His current position is an associate professor. His research areas cover the tribology of polymer composite, surface texture, and MD simulations.

associate from 1992 to 1998, an assistant professor 1998 to 2000, an associate professor from 2000 to 2004, and a professor from 2004 to 2006. Since March, 2006, he is a Changjiang Chair Professor at the Nanjing University of Aeronautics and Astronautics. In 2011, he was selected to "The Recruitment Program of Global Experts". He became ASME fellow in 2014. Now, he is the deputy director, State Key Laboratory of Mechanics and Control of Mechanical Systems. His main research interest is smart materials and structural systems, including development of piezoelectric materials and devices, vibration and noise control, structural health monitoring, and non-destructive testing.

Aeronautics and Astronautics from 1990. His current position is an associate professor. His research areas cover polymer composites and friction. 